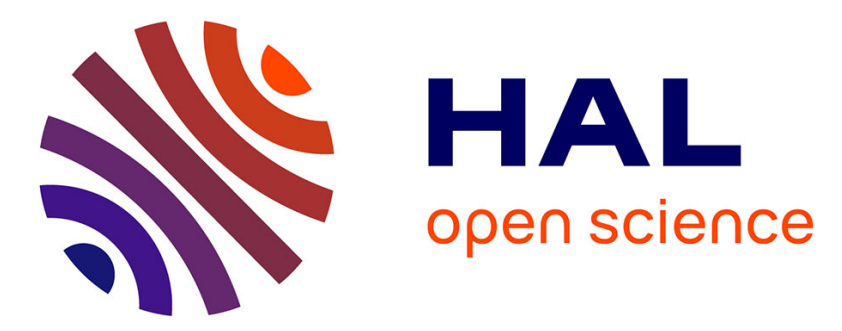

\title{
Using Fuzzy-based Approaches on Partner's Selection to Promote Sustainability on Collaborative Networks
}

\author{
Ricardo Santos, João Matias, Jose Soares, Pedro Carmona Marques, Victor
}

Anes

\section{- To cite this version:}

Ricardo Santos, João Matias, Jose Soares, Pedro Carmona Marques, Victor Anes. Using Fuzzybased Approaches on Partner's Selection to Promote Sustainability on Collaborative Networks. 22nd Working Conference on Virtual Enterprises (PRO-VE 2021), Nov 2021, Saint-Etienne, France. pp.5364, 10.1007/978-3-030-85969-5_5. emse-03324415

HAL Id: emse-03324415

https://hal-emse.ccsd.cnrs.fr/emse-03324415

Submitted on 24 Nov 2021

HAL is a multi-disciplinary open access archive for the deposit and dissemination of scientific research documents, whether they are published or not. The documents may come from teaching and research institutions in France or abroad, or from public or private research centers.
L'archive ouverte pluridisciplinaire HAL, est destinée au dépôt et à la diffusion de documents scientifiques de niveau recherche, publiés ou non, émanant des établissements d'enseignement et de recherche français ou étrangers, des laboratoires publics ou privés. 


\title{
Using Fuzzy-based Approaches on Partner's Selection to Promote Sustainability on Collaborative Networks
}

\author{
Ricardo Santos ${ }^{12}$, João Matias ${ }^{2}$, Jose Soares ${ }^{3}$, Pedro Carmona Marques ${ }^{14}$, \\ Victor Anes ${ }^{5}$ \\ ${ }^{1}$ ISEL- Instituto Superior de Engenharia de Lisboa, Instituto Politécnico de Lisboa \\ ${ }^{2}$ GOVCOPP - University of Aveiro, Portugal \\ ${ }^{3}$ ADVANCE, ISEG, Universidade de Lisboa, Portugal \\ ${ }^{4}$ EIGeS, Universidade Lusófona, Lisbon, Portugal \\ ${ }^{5}$ IDMEC-IST-UL, Lisboa, Portugal \\ ricardosimoessantos84@ua.pt
}

\begin{abstract}
Collaborative Networks (CN) are well-known by the literature, has a mean to achieve multiple innovations, resulted from the collaboration with a broad variety of partners to access different types of knowledge and skills. Despite its establishment, even in academia and in the corporate world, its implementation, constitutes a challenge, mainly when concerning to select the suitable partners to promote sustainable $\mathrm{CN}$ that attends the three dimensions of sustainability, regarding new product development's (NPD) projects. The lack of decision support frameworks, as well as the subjectivity around CN's manager's perception concerning this issue, motivates the development of this work.

Thus, this paper presents a soft computing-based approach to support CN's managers on partner's selection, regarding the NPD's projects on CN's context. The robustness of the approach developed here, will be assessed and validated through a case study, regarding the development of a green product.
\end{abstract}

Keywords: Sustainability, Collaborative Networks, New Product Development, Partner's selection, Soft Computing Approaches

\section{Introduction}

Finding suitable partners regarding several knowledge areas, is essential to obtain success with innovation in a collaborative environment [1]. In the last years, researchers have mainly focused their research on social environment effects, over the innovation levels, and regarding everyone [2-3]. For example, some works have highlighted the importance of providing some autonomy to the SMEs employees, when forming a teamwork from individuals with several competencies to achieve favorable work environments and high innovation levels from SME's employees [4]. Furthermore, the development of social networks in the SMEs, has provided their individuals with some 
sense of collectively, by sharing information with other SMEs to develop specific skills or even some expertise [5-6]

Additionally, some studies found on literature (e.g.[7]), states that innovation, achieved from collaborative networks $(\mathrm{CN})$, can lead toward to an efficient allocation of assets, improving at the same time the performance of an organization.

Several studies, with focus on partner selection methods for CN context, has been performed, in order to support managers on coordination of their $\mathrm{CN}$ to increase their innovative performance, with most of them, examining $\mathrm{CN}$ on behalf of different perspectives such as knowledge relevance (e.g.[8]), key CN positions (e.g.[9]), external available resources (e.g. [10].]), external cooperation by creating new knowledge or competences on behalf of new product development context (e.g. [11]), among others.

Some studies use Social Networks (SN) to locate the required external assets/resources for SMEs (e.g. [4]) while others, use SN to reach expert individuals (e.g. [3][10]).

All these studies highlight the importance of partner selection, as a purpose to support managers on coordination of their $\mathrm{CN}$ to increase their innovative performance.

The latest developments, regarding information systems, have created many available applications for professional use, with most of them, used by human resource (HR) professionals to search adequate partners for team building [8].

However, and due to the increasing requirements within SMEs on behalf of sustainable development, such as social and environment responsibilities, there are a few limited approaches to support managers on partner's assessment-based criteria, on behalf of the three dimensions of sustainability (Economic, Social and Environmental) [12].

Furthermore, the existence of some subjectivity within manager's perception, regarding the assessment of different partners, based on a set of criteria pre-established, is another issue to be accounted, since that the subjectivity increases with the number of managers/decision-agents on $\mathrm{CN}$ to perform the same evaluation. The inclusion of fuzzy logic-based methods, could also minimize such effects.

Thus, we intend to fill a gap on the literature, by presenting a model that integrates all these issues into a single approach, to promote sustainable CN's, through partner's selection and that answers to the following research question: what kind of soft computing-based approach to support CN's managers on partner's selection, regarding NPD's projects is possible to be achieved on a CN context?

The robustness of the proposed model, will be evaluated through a case study, based on a project developed on CN context, to create "green" energy to an industry. This case study will highlight some benefits achieved from this method, and some limitations as well, by pointing some future research to overcome them.

Therefore, this paper is organized as follows; Section 2, proposes the CN's model for assessing and choosing suitable partners, from a set of candidates to integrate the same network. Section 3, pretends to present the case study used here to assess method's robustness and the discussion of results. Then Section 4, ends this work with the conclusions and some future research remarks. 


\section{Research Method}

\subsection{Proposed Approach}

Following what was referred before, a Collaborative Network (CN), normally arises to conceive specific products/systems, by allocating different resources and competences, from a set of partners, to reach high levels of innovation at a lower cost. However, the partner's selection for the same $\mathrm{CN}$, arises multiple challenges, especially when it's intended to promote sustainability within the $\mathrm{CN}$ itself on developing such products/systems.

According to [12-13], sustainable development actions, can be divided into three main groups or dimensions; Economic, Social and Environmental.

From the literature, and regarding the criteria, normally used on partner's selection for $\mathrm{CN}$, we have found a set of criteria, which we have categorized, according to the three dimensions defined before, i.e.:

- Economic: Concerns all the criteria, that might impact the CN's economic and financial viability, which includes issues, mainly related with the organization's economic well-being [4][6], namely; facility's location, supply chain's channels (distribution points, transportation modes, etc.), scale (available) of operations, operation costs, financial situation and credibility, capacity of facilities, reliability of feedstock supply, among other criteria.

- Social: Concerns all the criteria, that might impact the CN's social viability, which can include issues mainly related with the organization's social wellbeing with its stakeholders [6][13], as well as reputation and share of knowledge/information issues, i.e.; social responsibility actions (e.g. employees' family members, health insurance, local population, etc.), work conditions, availability to share knowledge and information, knowledge relevance, reputation, number of partnerships firmed with other organizations, among other criteria.

- Environmental: Concerns all the criteria, that might impact the CN's environmental viability, which includes issues, mainly related with the organization's environmental responsibility [3][5], namely; Self-energy Greenhouse Gas (GHG) emissions, soil and water quality, circular economy policies, environment standards accreditation, among other criteria.

Based on those criteria, it was performed a framework to evaluate each partner's potential, as a candidate to be integrate in a CN. Thus, on Fig. 1, it's presented an example of the same framework, considering a set of criteria, categorized according to the dimensions of sustainability, referred before. 


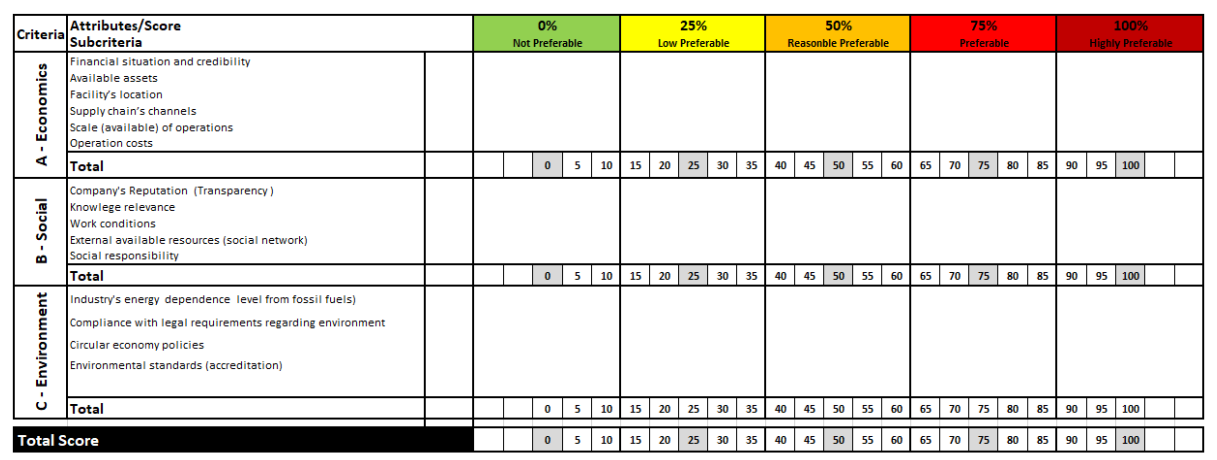

Fig. 1. Adopted criteria and pay-off table, used as a $1^{\text {st }}$ approach to define the model

Thus, and based on criteria presented on Fig.1, it can be defined an attribute $x$, which belongs to an alternative (potential partner) $i$, regarding to a sub criteria $j$, which is related to a dimension/criteria $g$, resulting therefore in $\left(x_{i j}^{g_{j}}\right)$. For each criterion $i$, related each one to a dimension of sustainability, corresponds to a set of sub criteria, which is then applied to assess each candidate's potential, by using Multi Attribute Value Theory (MAVT). Therefore, there is a dimension/criteria $g$, regarding to a specific sub criteria $j$, used here $\left(g_{j}\right)$, which can be represented as follows; A - Economic, B-Social and C- Environmental. In general, each attribute $x_{i j}^{g_{j}}$ can be defined, i.e:

$$
\begin{aligned}
& x_{i}=\left\{x_{i 1}, x_{i 2}, x_{i 3}, . ., x_{i n_{g}}\right\} \wedge n_{g}=\left\{n_{A}, n_{B}, n_{C}\right\} \wedge n_{A}, n_{B}, n_{C}, i, j \in \square \\
& g_{j} \in\left\{\left\{A_{1}, A_{2}, . ., A_{j}, \ldots A_{n_{A}}\right\} \cup\left\{B_{1}, B_{2}, . ., B_{j}, . ., B_{n_{B}}\right\} \cup\left\{C_{1}, C_{2}, . ., C_{j}, . . C_{n_{C}}\right\}\right\}
\end{aligned}
$$

Thus, each attribute $\left(x_{i j}^{g_{j}}\right)$ considered here, can be aggregated in just one pay-off table (Table 2 a)). Since that each attribute $\left(x_{i j}^{g_{j}}\right)$, works with different scales and units, the correspondent attribute values, were then converted by using MVAT, to its correspondent value $\left(v_{i j}^{g_{j}}\left(x_{i j}^{g_{j}}\right)\right)$, by using the "worst" and "better" results, obtained through a set of alternatives, and related to each criteria $g_{j}$, i.e.:

$$
x_{i j}^{\left(g_{j}\right)} \longrightarrow\left(\frac{\left|x_{i j}^{\left(g_{j}\right)}-x_{i j(\text { worst })}^{\left(g_{j}\right)}\right|}{\left|x_{i j(\text { better })}^{\left(g_{j}\right)}-x_{i j(\text { worst })}^{\left(g_{j}\right)}\right|}\right) \longrightarrow v_{i j}^{\left(g_{j}\right)}\left(x_{i j}^{\left(g_{j}\right)}\right)
$$

The new values, referred to each $v_{i j}^{\left(g_{j}\right)}\left(x_{i j}^{\left(g_{j}\right)}\right)$, have originated a new pay-off table, which is the result of the conversion of Table 2 a), to Table 2 b), by using (3). 


\begin{tabular}{c|cccccccccccc}
$x_{i j}^{g j}$ & $A 1$ & $A 2$ & $\ldots$ & $A \mathrm{n}_{A}$ & $\mathrm{~B} 1$ & $\mathrm{~B} 2$ & $\ldots$ & $\mathrm{Bn} \mathrm{n}_{B}$ & $\mathrm{C} 1$ & $\mathrm{C} 2$ & $\ldots$ & $\mathrm{Cn}_{C}$ \\
\hline$X_{1}$ & $x_{11}^{A 1}$ & $x_{12}^{A 2}$ & $\ldots$ & $x_{1}^{A n_{A}}$ & $x_{11}^{B 1}$ & $x_{12}^{B 2}$ & $\ldots$ & $x_{1}^{B n_{B}}$ & $x_{11}^{C 1}$ & $x_{12}^{C 2}$ & $\ldots$ & $x_{1 n_{C}}^{C n_{C}}$ \\
$X_{2}$ & $x_{21}^{A 1}$ & $x_{22}^{A 2}$ & $\ldots$ & $x_{2 n_{A}}^{A n_{A}}$ & $x_{21}^{B 1}$ & $x_{22}^{B 2}$ & $\ldots$ & $x_{2 n_{B}}^{B n_{B}}$ & $x_{21}^{C 1}$ & $x_{22}^{C 2}$ & $\ldots$ & $x_{2 n_{C}}^{C n_{C}}$ \\
$\ldots$ & $\ldots$ & $\ldots$ & $\ddots$ & $\ldots$ & $\ldots$ & $\ldots$ & $\ldots$ & $\ldots$ & $\ldots$ & $\ldots$ & $\ldots$ & $\ldots$ \\
$X_{n}$ & $x_{n 1}^{A 1}$ & $x_{n 2}^{A 2}$ & $\ldots$ & $x_{n n_{A}}^{A n_{A}}$ & $x_{n 1}^{B 1}$ & $x_{n 2}^{B 2}$ & $\ldots$ & $x_{n n_{B}}^{B n_{B}}$ & $x_{n 1}^{C 1}$ & $x_{n 2}^{C 2}$ & $\ldots$ & $x_{n n_{C}}^{C n_{C}}$
\end{tabular}

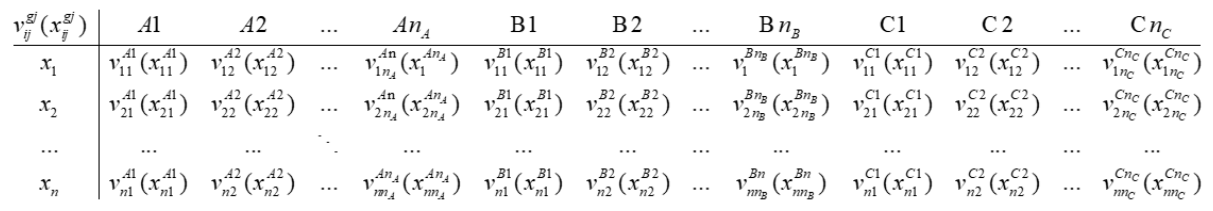

b)

Fig. 2.Pay-off table, used to define model's criteria: (a) $x_{i j}^{\left(g_{j}\right)}$; (b) $v_{i j}\left(x_{i j}^{\left(g_{j}\right)}\right)$.

Through the attributes previously defined, and by using fuzzy logic techniques, it was achieved the correspondent value functions $V_{i}^{A}\left(x_{i}^{A}\right), V_{i}^{B}\left(x_{i}^{B}\right)$ and $V_{i}^{C}\left(x_{i}^{C}\right)$, regarding each sustainability's dimension. Then, and by using an additive model, based on MAVT approach, it was achieved a unique expression to aggregate all dimensions, to assess each alternative/potential partner. This function is then weighted by a weight factor $\left(\omega_{g}\right)$, expressing thus, the relative importance given to the dimension of each sustainability, resulting therefore in the final assessment function, i.e.:

$$
V_{i}\left(X_{i}\right)=V_{i}\left(V_{i}^{A}\left(x_{i}^{A}\right), V_{i}^{B}\left(x_{i}^{B}\right), V_{i}^{C}\left(x_{i}^{C}\right)\right)=\omega_{A} \cdot V_{i}^{A}\left(x_{i}^{A}\right)+\omega_{B} \cdot V_{i}^{B}\left(x_{i}^{B}\right)+\omega_{C} \cdot V_{i}^{C}\left(x_{i}^{C}\right)
$$

With $\omega_{A}, \omega_{B}, \omega_{C}$, being achieved by using Analytical Hierarchical Process (AHP) method, as it presented and described on following sections.

\subsection{Model's Architecture, Fuzzy Modelling and Linguistic Variables}

The proposed architecture, intends to integrate all the issues, referred before with fuzzy inference systems, to support managers into the development of a product on behalf of Collaborative Networks (CN) (Fig.3). Additionally, the integration of Fuzzy Systems, has the purpose of incorporating the ambiguity and subjectivity, related with human perception on assessing each potential partner, according to a set of criteria previously defined.

The proposed approach is presented on Fig.3. 


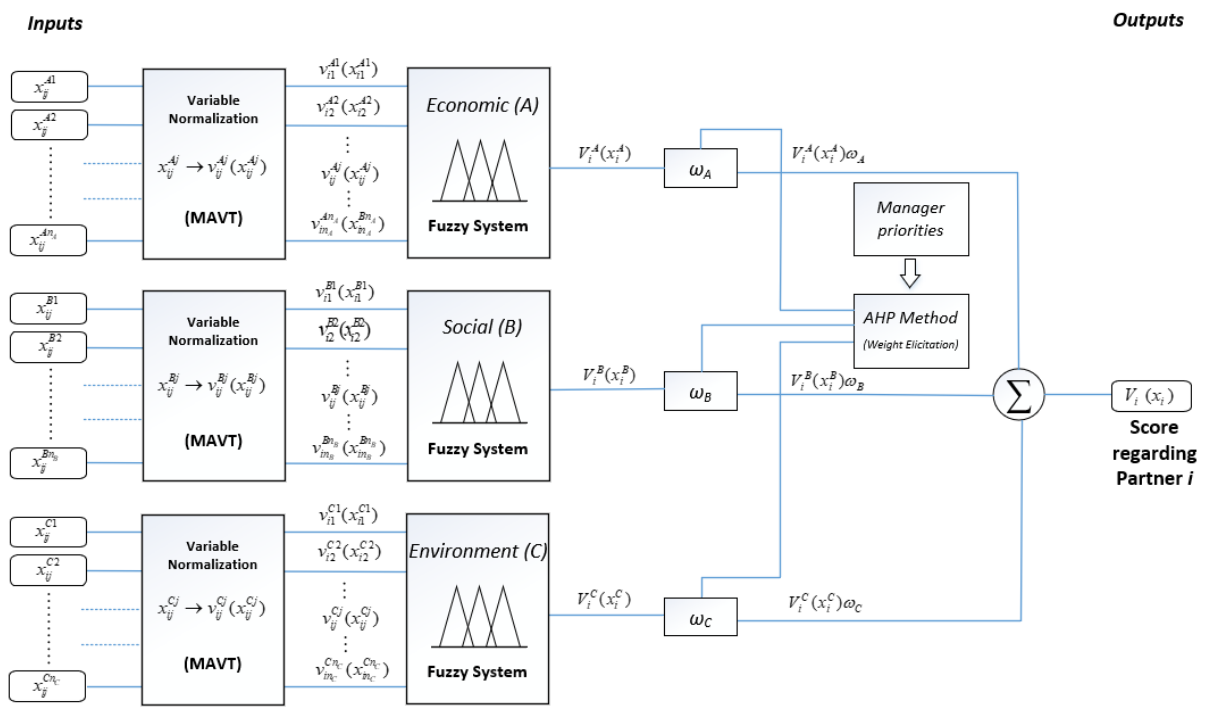

Fig. 3. Proposed model.

Based on Fig.3, each alternative/potential partner $i$, has a set of individual scores $v_{i j}^{g j}\left(x_{i j}^{g j}\right)$, which are correspondent, each one, to a given criteria/dimension $(g)$, related to each sub criteria $j$, which is then used as an input regarding for each correspondent Fuzzy System (related each one to a specific dimension/criteria). By using a fuzzy inference mechanism, and through a set of inference rules, regarding a sentence from the type of "If...And...Then", it is obtained the overall score of each criterion, regarding each alternative/potential partner $i\left(V_{i}^{g}\left(x_{i}^{g}\right)\right)$.

Therefore, each $V_{i}^{g}\left(x_{i}^{g}\right)$, regarding the dimensions considered here (A,B and C), are achieved, by using a set of functions, based on the inputs $v_{i j}^{g j}\left(x_{i j}^{g j}\right)$, i.e.:

$$
V_{i}^{g}\left(x_{i}^{g}\right)=v_{i 1}^{g 1}\left(x_{i 1}^{g 1}\right) \cap v_{i 2}^{A 2}\left(x_{i 2}^{g 2}\right) \cap \ldots . . v_{i j}^{g j}\left(x_{i j}^{g j}\right) \cap \ldots . \cap v_{i n_{g}}^{g n_{g}}\left(x_{i n_{g}}^{g n_{g}}\right)
$$

Thus, and through $V_{i}^{A}\left(x_{i}^{A}\right), V_{i}^{B}\left(x_{i}^{B}\right)$ and $V_{i}^{C}\left(x_{i}^{C}\right)$, it is achieved an expression to assess each alternative/potential partner $i$, i.e.:

$V_{i}\left(x_{i}\right)=V_{i}\left(V_{i}^{A}\left(x_{i}^{A}\right), V_{i}^{B}\left(x_{i}^{B}\right), V_{i}^{C}\left(x_{i}^{C}\right)\right)=\omega_{A} \cdot V_{i}^{A}\left(x_{i}^{A}\right)+\omega_{B} \cdot V_{i}^{B}\left(x_{i}^{B}\right)+\omega_{C} \cdot V_{i}^{C}\left(x_{i}^{C}\right)$

With $\omega_{A}, \omega_{B}, \omega_{C}$, be achieved by using Analytical Hierarchical Process (AHP) method, and satisfying the following condition: 


\subsection{Linguistic Variables}

$$
\omega_{A}+\omega_{B}+\omega_{C}=1
$$

Concerning the linguistic variables and based on ([13][15]) it is advised that the number of linguistic levels should not surpass nine, given the eventuality of surpassing the decision-agent's perception's limits, when it's wanted to discriminate such values.

Thus, and based on Fuzzy Systems, presented on Figs. 3 and 4, it was defined 5 linguistic levels, as well as their correspondent pertinence functions (Tables 1), regard$\operatorname{ing} v_{i j}^{g j}\left(x_{i j}^{g j}\right)$ and $v_{i}^{g j}\left(x_{i}^{g j}\right)$ values. Each pertinence function, makes use of a triangular type function, with the correspondent parameters $\gamma, \beta$ and $\alpha$.

Table 1. Linguistic Levels, regarding $v_{i j}^{g j}\left(x_{i j}^{g j}\right)$ and $v_{i}^{g j}\left(x_{i}^{g j}\right)$ values

\begin{tabular}{|c|c|c|}
\hline Linguistic Levels & Description & Parameters $[\gamma, \boldsymbol{\beta}, \boldsymbol{\alpha}]$ \\
\hline Not Preferable & There is no evidence, accounting this issue. & $(0,0,0.25)$ \\
\hline Low Preferable & There is some evidence, accounting this issue. & $(0,0.25,0.50)$ \\
\hline Reasonble Preferable & There is evidence, accounting this issue. & $(0.25,0.50,0.75)$ \\
\hline Preferable & There is a strong evidence, accounting this issue. & $(0.5,0.75,1.0)$ \\
\hline Highly Preferable & There is a clear evidence, accounting this issue. & $(0.75,1,1)$ \\
\hline
\end{tabular}

Thus, and based on the parameters presented on Table 1, it's converted the linguistic values into a numerical format, by establishing a set of intervals, to be further aggregated, by using expression (8).

\subsection{Fuzzy Deployment and Software's Implementation}

Based on Fig.3, each Fuzzy System, was deployed by using Matlab ${ }^{\circledR}$ software (version R2018a), which has included the membership functions and the inference rules previously defined (Table 1).

As it stated before, and regarding each Fuzzy Systems defined here, it was adopted triangular functions, with the correspondent parameters, being obtained from Table 1. The inference rules, were deployed by using Mamdani's inference mechanism (Fig. 4), given its intuitive method, which is well-suited to the human inputs and its widely acceptance on literature [15]. 


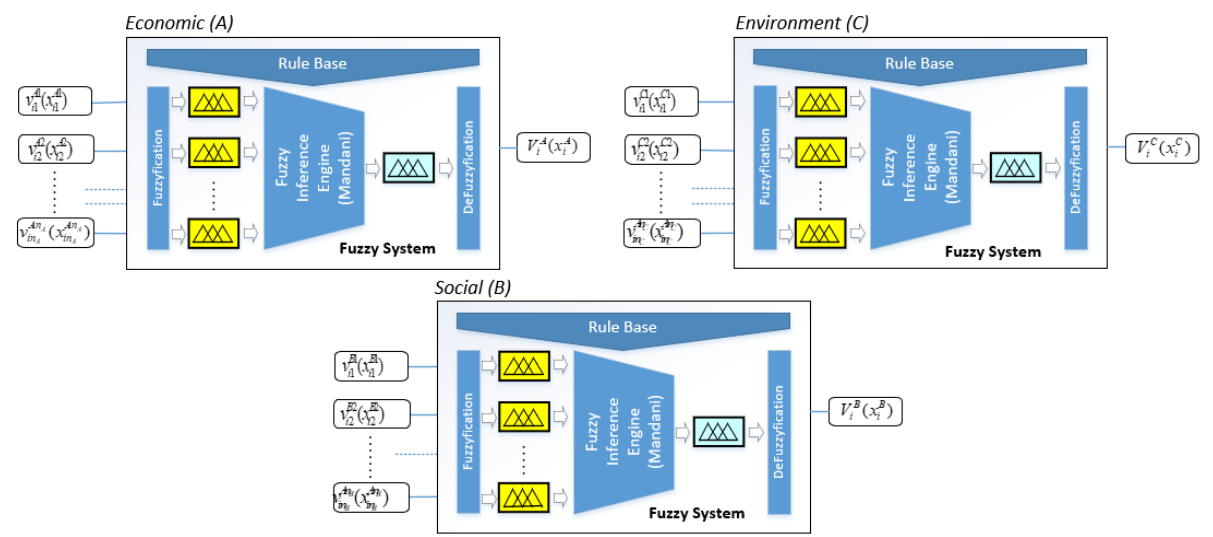

Fig. 4. Fuzzy Systems, regarding $V_{i}^{A}\left(x_{i}^{A}\right), V_{i}^{B}\left(x_{i}^{B}\right)$ and $V_{i}^{C}\left(x_{i}^{C}\right)$ values

Regarding the defuzzification method for each FS's, it was adopted centroid approach, mainly due its widely acceptance in other works existed on literature ([15]).

\section{Case Study}

For model's validation, we have used a case study based on a $\mathrm{CN}$, which was created to develop a system, to produce green electric energy to an industry, with the purpose of being $\mathrm{CO}_{2}$ free emissions, regarding its energy consumption.

This system allows to an industry to produce its own energy, by integrating photovoltaic, with hydrogen systems. The CN's purpose, is to make this system an integrated product, to be launched to the market, to be further deployed in industries, with an installed power, with valued, ranged between $50-100 \mathrm{~kW}$.

In a $1^{\text {st }}$ stage, this system, was tested in a prototype version, by feeding a small industry of $70 \mathrm{~kW}$, to be self-sufficient from the electric public grid. The system itself is formed by a set of components, where besides the PV System, with its main components (the converter and PV panels), its formed by the main components regarding hydrogen systems (e.g., Fuel Cell, $\mathrm{H}_{2}$ and $\mathrm{O}_{2}$ tanks, and Electrolyze) and the other components, needed to perform the supervision, control and data acquisition of the system. Each part/component of the system, is developed/produced by a unique organization (partner), or even a set of them. The organization can have several types, which means that it can be public or even private (R\&D, University, Company, etc.).

All the partners involved, contributes each one to the development part of a system, by exchanging resources and competencies (as depicted in Fig.5). In this case, the Collaborative Network $(\mathrm{CN})$ has 12 partners, which have different nature, and they come from different sectors.

For the modelling of different resources and competencies exchanged on this $\mathrm{CN}$, between the different $\mathrm{CN}$ partners, we have used the framework proposed by [13], to manage enterprises' innovation in open innovation contexts (Fig. 5). 


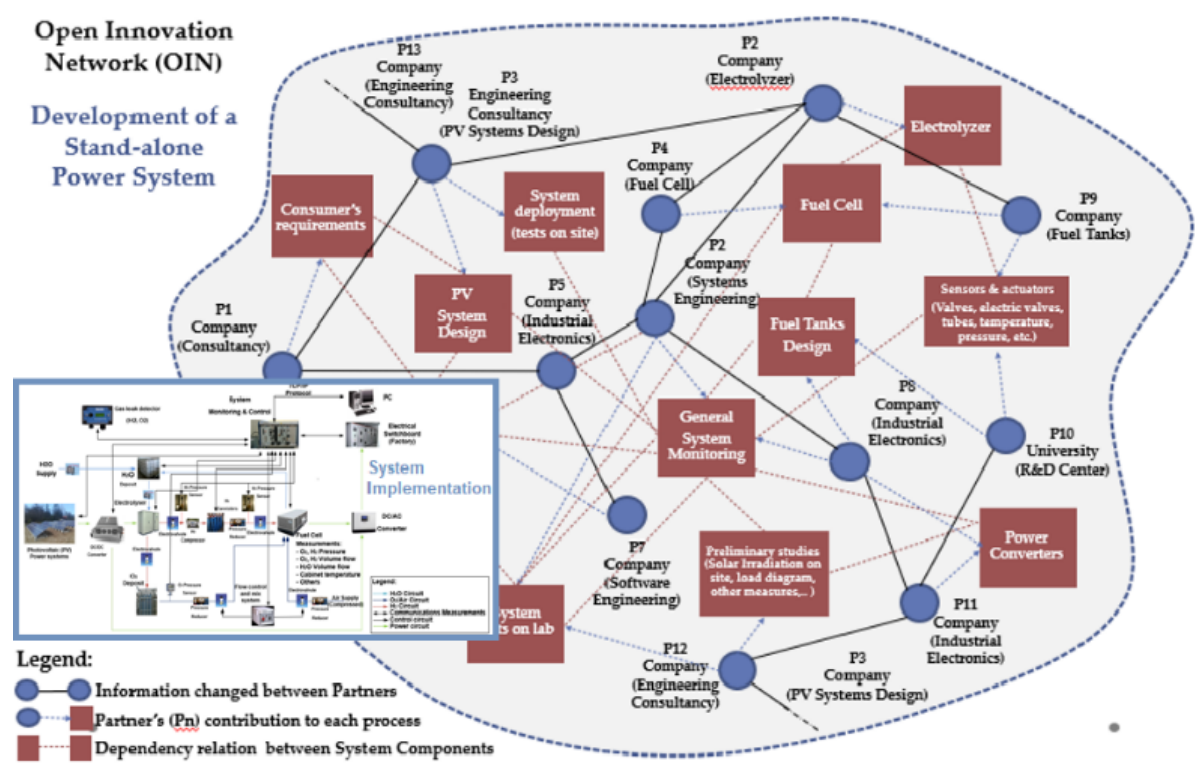

Fig. 5. CN regarding the developed system [13]

By following the same approach, and based on the network presented on Fig.5, we can systematize the resources and competencies exchanged between the partners involved, by defined as a contribution from each partner to each process, which are regarded to each system part under development, as well as the relationship between each part/component of the system.

Such contribution can be better understood by presenting an example on Table 2 , where it can be observed some of the processes of the system under development, followed by the description of partners/actors involved.

Table 2. Some of the processes, used on behalf of the system under development.

\begin{tabular}{|c|c|c|}
\hline Process Reference & Description & Partners \\
\hline$\ldots$ & $\ldots$ & $\ldots$ \\
\hline K02Pr3 & PV System design & P3, P12 \\
\hline$\ldots$ & $\ldots$. & $\ldots$ \\
\hline K01Pr6 & Human Machine Interface (HMI) & P6 P? P? \\
\hline K02Pr5 & Systems tests on lab & P2,P6 e P12 \\
\hline K02Pr5 & General System Monitoring and Control & P6, P7, P10 \\
\hline$\ldots$ & $\ldots$ & $\ldots$ \\
\hline
\end{tabular}

To apply the model presented here, we have selected from Table 2, the process, with Process Reference K01Pr6 (Human Machine Interface (HMI)), where the Chief Technology Officer, as well as the CN's board of managers, wants to select two more partners to join to the existence one, already established (Partner P6). The purpose is to increase the goal of innovation level regarding the HMI to be developed, which was previously defined by the CN's management. 
Therefore, a group of managers, have made use of the model's inputs, and based on the three dimensions of sustainability, already defined.

They have contacted a group of potential partners, to be further assessed as candidates, to fulfill the two available places of partners to be added to the $\mathrm{CN}$ defined here. By using the Fuzzy Systems approach, proposed on Figs 3 and 4, as well as the linguistic variables defined on Table1, and according to a set of rules, we have achieved the correspondent outputs, regarding each partner to be assessed (Table 3).

The weights, corresponding each one to a sustainability's dimension, where then defined by using the Analytical Hierarchical Process (AHP) method.

Table 3. Model's inputs and the correspondent outputs

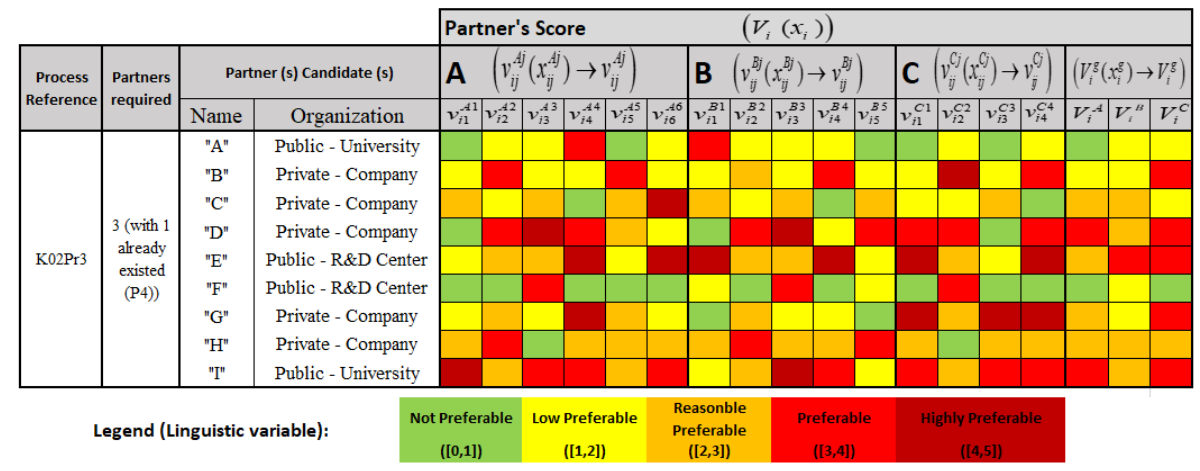

The results, presented on Table 3, were obtained by using the fuzzy inference systems, referred before (Fig.3), where, and based on a set of linguistic values, it was then converted into quantitative ones, through the deployment of a series of intervals, in order to achieve the score of each one of the 9 (potential/candidate) partners considered here, regarding each one, to one of the three sustainability's dimensions. Then, and by applying the correspondent weights, previously achieved, it was achieved the overall score, regarding each one of the 9 partners considered here (Table 4).

Table 4. Overall results, regarding each candidate (potential partner) to be selected.

\begin{tabular}{|c|c|c|c|c|c|c|c|c|c|c|c|c|c|c|c|}
\hline \multirow{2}{*}{$\begin{array}{c}\text { Process } \\
\text { Reference }\end{array}$} & \multirow{2}{*}{$\begin{array}{l}\text { Partners } \\
\text { required }\end{array}$} & \multicolumn{10}{|c|}{ Partner (s) Candidate (s) } & \multicolumn{4}{|c|}{ Partner(s) Selected (order of preference) } \\
\hline & & Nr. & Name & Organization & $V_{i}^{A}$ & $V_{i}^{B}$ & $V_{i}^{C}$ & $\omega_{A}$ & $\omega_{B}$ & $\omega_{c}$ & $V_{i}$ & Rank & Name & Organization & $V_{i}$ \\
\hline \multirow{9}{*}{ K02Pr3 } & \multirow{9}{*}{$\begin{array}{c}3 \text { (with 1 } \\
\text { already } \\
\text { existed } \\
(\mathrm{P} 4))\end{array}$} & 1 & "A" & Public - University & 0,2 & 1,1 & 1,9 & 0,27 & 0,21 & 0,52 & 1,27 & 1st & "D" & Private - Company & \\
\hline & & 2 & "B" & Private - Company & 1,3 & 1,8 & 3,6 & 0,36 & 0,14 & 0,50 & 2,52 & 2nd & "E" & Public - University & 3,22 \\
\hline & & 3 & "C" & Private - Company & 2,1 & 2,7 & 1,5 & 0,30 & 0,22 & 0,48 & 1,94 & 3 rd & "I" & Public - University & 3,14 \\
\hline & & 4 & "D" & Private - Company & 3,1 & 2,8 & 3,8 & 0,39 & 0,17 & 0,44 & 3,36 & 4th & "H" & Private - Company & 2,56 \\
\hline & & 5 & "E" & Public - University & 2,1 & 3,7 & 3,6 & 0,27 & 0,21 & 0,52 & 3,22 & 5 th & "B" & Private - Company & 2,52 \\
\hline & & 6 & "F" & Private - Company & 0,7 & 1,8 & 0,9 & 0,36 & 0,14 & 0,50 & 0,95 & 6th & "C" & Private - Company & 1,94 \\
\hline & & 7 & "G" & Private - Company & 2,9 & 1,4 & & 0,30 & 0,22 & 0,48 & 1,18 & 7th & "A" & Public - University & 1,27 \\
\hline & & 8 & "H" & Private - Company & 2,5 & 2,1 & 2,8 & 0,39 & 0,17 & 0,44 & 2,56 & 8th & "G" & Private - Company & 1,18 \\
\hline & & 9 & "I" & Public - University & 3,2 & 2,4 & 3,4 & 0,27 & 0,21 & 0,52 & 3,14 & 9th & "F" & Private - Company & 0,95 \\
\hline
\end{tabular}

Legend (Preference degree): 
After the score of each partner took place, it was re-ordered the candidates according to its overall score (Table 4 ), to define the order of preference. Therefore, and according to Table 4 , the 2 candidates, needed for process K02Pr3 with more preference degree, are the private company " $D$ ", followed by the public university "E".

We can also select the candidate with more score related to a specific dimension of sustainability, which can be useful when we want to prioritize the candidates according to a specific dimension. We can also consider the next candidates to fulfill the $\mathrm{CN}$ needs, and in case of a contingency occur (e.g., private company " $D$ " has quitted after the negotiations took place), which allows to select the next candidate with the highest score (in this case will be the private company "D"). Additionally, if we want to add just one partner, the selected partner would be the partner with the highest rank i.e., the private company " $\mathrm{D}$ ", or if we want to select three more partners (instead of two), the candidates would be the first 3 (i.e., organizations "D", "E" and "I") and so on.

\section{Conclusions of the Work}

The approach presented here was developed to answer the proposed research question, thus presenting a new soft model, that support CN's management on partner's selection, regarding NPD and the three sustainable dimensions (Economic, Social and Environmental) by assessing a set of potential partners, assessing and prioritizing them.

Besides by the assessment and prioritization of each candidate, according to its attributes, it was also possible to perceive in which sustainability's dimension, each candidate is more "stronger" (suitable), according to the CN's objectives, which is defined by the priorities, which are established by the CN's managers, through AHP method.

Furthermore, it is even possible to face eventual contingencies from one or more partners (e.g., unavailability of selected partner after negotiations takes place), by selecting other partners with the next highest score.

The integration of Fuzzy Logic methods, also allows to reduce the ambiguity, related with the subjectivity around CN's manager perception on defining the attributes, needed to preform each assessment.

However, the limitations found with this model, allows to establish some future work, which will be then used to perform some enhancements, such as the addition of neural networks to predict CN's manager priorities, regarding sustainability's dimensions, or even additional sub criteria, more related with social networks.

\section{References}

1. Mansor, N., Yahaya, S., N., and Okazaki, K., Risk factors affecting new product development (NPD), Int. J. Recent Res. Appl. Stud. , vol. 27, no. 1,18-25 (2016)

2. Obradović, T., Vlačić, B, Dabić, M.,Open innovation in the manufacturing industry: A review and research agenda,Technovation,Volume 102, (2021),102221,ISSN 0166-4972, https://doi.org/10.1016/j.technovation.2021.102221.

3. Hameed, W.U., Nisar, Q.A., Wu, H., Relationships between external knowledge, internal innovation, firms' open innovation performance, service innovation and business 
performance in the Pakistani hotel industry, International Journal of Hospitality Management,Volume 92,2021,102745,ISSN 0278-4319, https://doi.org/10.1016/j.ijhm.2020.102745.

4. Guertler, M.R., Sick, N., Exploring the enabling effects of project management for SMEs in adopting open innovation - A framework for partner search and selection in open innovation projects, International Journal of Project Management, (2021), Pages 102-114,ISSN 02637863, https://doi.org/10.1016/j.ijproman.2020.06.007.

5. Goyal, S., Ahuja, M., Kankanhalli, A., Does the source of external knowledge matter? Examining the role of customer co-creation and partner sourcing in knowledge creation and innovation, Information \& Management, Volume 57, Issue 6,2020,103325,ISSN 03787206,https://doi.org/10.1016/j.im.2020.103325.

6. Santamaría, L., Nieto, M.J., Rodríguez, A., Failed and successful innovations: The role of geographic proximity and international diversity of partners in technological collaboration, Technological Forecasting and Social Change, Volume 166, (2021),120575, ISSN 00401625,https://doi.org/10.1016/j.techfore.2021.120575.

7. Grace, M. F., Leverty, J. T., Phillips, R. D., Shimpi, P.: The value of investing in enterprise risk management. Journal of Risk and Insurance, vol. 2, no. 82, 289-316 (2015)

8. Fenfen Wei, Nanping Feng, Shanlin Yang, Qinna Zhao, A conceptual framework of twostage partner selection in platform-based innovation ecosystems for servitization, Journal of Cleaner Production,Volume 262, 2020,121431,ISSN 0959-6526, https://doi.org/10.1016/j.jclepro.2020.121431

9. E.Y. Li , C.H. Liao, H.R. Yen, Co-authorship networks and research impact: a social capital perspective, Res. Policy 42 (9) (2013) 1515-1530 .

10. Markovic, S., Bagherzadeh, M., Vanhaverbeke, W., Bogers, M., Managing business-tobusiness open innovation: A project-level approach, Industrial Marketing Management, Volume 94, 2021, Pages 159-163, ISSN 0019-8501, https://doi.org/10.1016/j.indmarman.2021.02.009.

11. M. Coscia , G. Rossetti , D. Pennacchioli , F.Giannotti , "You KnowBecauseI Know": amultidimensionalnetworkapproach to human resources problem, in: ACM International Conference on Advances in Social Networks Analysis and Mining, 2013, pp. 434-441.

12. Dias, A.S.M.E.; Abreu, A.; Navas, H.V.G.; Santos, R. Proposal of a Holistic Framework to Support Sustainability of New Product Innovation Processes. Sustainability 2020, 12, 3450. https://doi.org/10.3390/su12083450

13. Santos, R.; Abreu, A.; Dias, A.; Calado, J.M.F.; Anes, V.; Soares, J. A Framework for Risk Assessment in Collaborative Networks to Promote Sustainable Systems in Innovation Ecosystems. Sustainability 2020, 12, 6218. https://doi.org/10.3390/su12156218

14. Victoria Uren, Tim Miller, Raffaello Da Campo, Aba-Sah Dadzie, A model for partner selection criteria in energy from waste projects, Journal of Cleaner Production,Volume 279,2021,123582,ISSN 0959-6526,https://doi.org/10.1016/j.jclepro.2020.123582.

15. Abreu, A., Santos, R., M.F. Calado, J., \& Requeijo, J. (2020). A Fuzzy Logic Model to Enhance Quality Management on R\&D Units. KnE Engineering, 5(6), 285-298. https://doi.org/10.18502/keg.v5i6.7047 